\title{
ANÁLISE DA EDUCAÇÃO AMBIENTAL NA UNIVERSIDADE FEDERAL DE CAMPINA GRANDE (UFCG) NOS ANOS DE 2002 A 2017: DISCIPLINAS E PROJETOS
}

\author{
Catyelle Maria de Arruda Ferreira ${ }^{1}$ \\ Prof. Dr. Sérgio Murilo Santos de Araújo² \\ Ary Gustavo da Silva Cesar ${ }^{3}$
}

Resumo: O artigo aborda a efetivação da Educação Ambiental do Campus sede da Universidade Federal de Campina Grande - PB através da análise sobre o Ensino, Pesquisa e Extensão entre 2002 a 2017, analisando os fluxogramas dos 105 cursos de graduação da UFCG que possuem na grade curricular obrigatória disciplinas que se aproximam da temática EA, a Pesquisa e Extensão foram analisados o quantitativo e qualitativo dos projetos, dissertações e teses. Conclui-se, que a Lei 9.795, não está presente nas ações realizadas na universidade, como também não é preponderante no desenvolvimento das atividades voltadas ao ensino, pesquisa e extensão, sendo incipientes nas disciplinas obrigatórias nos cursos de graduação.

Palavras-chave: Políticas Ambientais; Ensino Superior; Educação Ambiental Formal; Currículo.

\footnotetext{
1 Universidade Federal de Campina Grande. E-mail: ferreiracma@yahoo.com.br

2 Universidade Federal de Campina Grande. E-mail: sergiomurilosa.ufcg@gmail.com

${ }^{3}$ Instituto de Pesquisa e Desenvolvimento Sustentável. E-mail: ary_gustavo_silva@hotmail.com
}

Revbea, São Paulo, V. 13, № 1: 87-107, 2018.

revista brasileira educação ambiental 


\section{Introdução}

Após a década de 1970 os educadores interessados na questão ambiental elaboraram diversas concepções de Educação Ambiental, que nortearam várias práticas educativas no Brasil. Estes mentores consideram a Educação Ambiental como um componente relevante na reflexão e construção de diferentes visões de mundo que fundamentam as ações educativas, quer nos contextos formais ou informais. Para isso, segundo os educadores, ela necessita apresentar características interdisciplinares, sendo orientada para solução dos problemas presentes na realidade local, adequando-os ao público alvo e à realidade dos mesmos, pois de acordo com Dias (2004), os problemas ambientais devem ser compreendidos primeiramente em seu contexto local e, depois, em nível global.

Acredita-se que a Educação Ambiental tem o grande desafio de desenvolver novos conhecimentos e habilidades, valores e atitudes, objetivando a melhoria da qualidade ambiental e, efetivamente, a elevação da qualidade de vida para as gerações presentes e futuras. Por isso, é indispensável tratá-la a partir de sua vinculação direta com a ética e a cidadania, situando-a numa reflexão mais ampla que envolve uma visão sociológica e uma visão política de mundo.

Reigota (2006, p.10) afirma que: "a Educação Ambiental deve ser entendida como educação política, no sentido de que ela reivindica e prepara os cidadãos para exigir justiça social, cidadania nacional e planetária, autogestão e ética nas relações sociais e com a natureza". A Educação Ambiental deve ser considerada como uma alternativa e/ou instrumento no processo de aprendizagem permanente entre os indivíduos, estes deverão adquirir consciência da importância e dos cuidados que o meio ambiente necessita.

A universidade, neste contexto, tem importante papel na formação e construção de um ser humano conhecedor e modificador da realidade, baseado nos princípios da sustentabilidade e da Educação Ambiental, torna-se um educador ambiental capaz de pensar e agir sobre sua própria realidade.

Entende-se por Educação Ambiental, de acordo com a Lei 9.795/99, os processos por meio dos quais o indivíduo e a coletividade constroem valores sociais, conhecimentos, habilidades, atitudes e competências voltadas para a conservação do meio ambiente, bem de uso comum do povo, essencial à sadia qualidade de vida e sua sustentabilidade.

Assim, a EA é um componente essencial e permanente da educação nacional, dessa forma, é de responsabilidade das instituições educativas promover a Educação Ambiental de maneira integrada aos programas educacionais que desenvolvem.

Segundo Leff (2001) grande parte dos problemas ambientais que estamos vivenciando hoje é consequência de nossas atitudes, em que tais atitudes colocam a humanidade nos extremos dos limites. Segundo o autor a crise ambiental que vivenciamos é o conflito do nosso tempo e:

Revbea, São Paulo, V. 13, № 1: 87-107, 2018. 
apresenta-se a nós como um limite no real, que ressignifica e reorienta o curso da história: limite do crescimento econômico e populacional; limite dos desequilíbrios ecológicos e das capacidades de sustentação da vida; limite da pobreza e da desigualdade social (LEFF, 2001, p.191).

É sabido que mudanças rápidas precisam ser adotadas por toda a humanidade para a resolução de tais limites, tendo como grande vilão a busca de um crescimento inconsequente, que por si só não é capaz de solucionar os problemas quer sejam estes sociais, econômicos ou ambientais por ele mesmo criado.

Em vista disso, torna-se necessário atingir o máximo possível de indivíduos com o alerta sobre a importância em se manter a coesão entre a humanidade e o planeta Terra, promovendo a sustentabilidade de maneira plena e ativa. Nesse sentido, a maior força que pode impulsionar uma mudança é a Educação, mesmo que esta seja aplicada ao público de maiores vivências, caso específico deste trabalho.

\section{Origem da Educação Ambiental}

A Educação Ambiental (EA) surgiu no contexto da "crise ambiental", numa tentativa de encontrar um instrumento eficaz no enfrentamento dos graves problemas que assolam a "Sociedade de riscos". Este termo foi utilizado pela primeira vez na Inglaterra, porém ficou mais conhecido de forma ampla a partir da realização das Conferências mundiais sobre Meio Ambiente e Desenvolvimento.

Em 1972, na capital da Suécia reuniram-se representantes de 113 países para sediar a Conferência das Nações Unidas sobre o Meio Ambiente Humano, que ficou reconhecida mundialmente como a Conferência de Estocolmo. No documento elaborado neste contexto, em sua recomendação no 96, versando sobre a Educação e Meio Ambiente, apresentou-se a importância da realização de um Programa de Educação Ambiental como estratégia essencial de combate à crise ambiental e melhoria da qualidade de vida.

Em 1973, foi criado o Programa das Nações Unidas para o Meio Ambiente - PNUMA (United Nations Environment Programme - UNEP), objetivando coordenar políticas e viabilizar um "Plano de Ação Mundial", através de ações dirigidas aos processos de avaliação e gestão ambiental; e medidas de apoio neste campo do meio ambiente em nível mundial.

No término de 1975, a Organização das Nações Unidas para a Educação, a Ciência e a Cultura (UNESCO), realizou em Belgrado, lugoslávia, - Encontro Internacional de Educação Ambiental, produzindo a Carta de Belgrado, um dos mais importantes documentos elaborados na década, dirigindo a atenção mundial à necessidade de construção de uma nova ética

ambiental. Sendo assim, considerou-se que a Educação Ambiental deve 
apresentar características multidisciplinares, continuada e integrada às diferenças regionais e voltada aos interesses nacionais.

Tais eventos foram preparatórios para a Conferência de Tbilisi, realizada em Outubro de 1977, designada "Primeira Conferência Intergovernamental sobre Educação Ambiental", organizada pela UNESCO, em colaboração com o Programa das Nações Unidas para o Meio Ambiente. Ressaltou-se nesta Conferência, dentre outros aspectos, a obrigação da interdisciplinaridade para resgatar a percepção ambiental por meio da visão da totalidade, distanciandose da fragmentação ocorrida nas diversas áreas do conhecimento.

No Brasil foram realizados diversos encontros, seminários e debates preparatórios, a fim de elaborar o primeiro documento oficial do governo brasileiro sobre Educação Ambiental, assinado em 1975 pela Secretaria Especial do Meio Ambiente e pelo Ministério do Interior, intitulado: "Educação Ambiental". Este documento foi apresentado na Conferência de Tbilisi.

Após a Conferência de Tbilisi, o Ministério de Educação e Cultura (MEC) e a Companhia Estadual de Tecnologia e Saneamento Ambiental (CETESB) promulgaram o documento "Ecologia: uma Proposta para o ensino de $1^{\circ}$ e $2^{\circ}$ graus", que tinha a finalidade de auxiliar a prática pedagógica.

A Recomendação № 13 da Conferência de Tbilisi esclarece que as instituições de ensino superior apresentam uma importante função de "transmitir aos estudantes os conhecimentos básicos essenciais para que sua futura atividade profissional redunde em benefício do meio ambiente"; recomenda que isso aconteça de forma interdisciplinar e, por fim, sugere que a elaboração de recursos pedagógicos seja uma prática da $E A$, através da cooperação entre instituições universitárias, visando "preparar especialistas em EA".

A Conferência Rio-92 em 1992, realizada no Rio de Janeiro elaborou a Agenda 21, ou seja, um plano de ação para o século $X X I$, visando à sustentabilidade da vida na terra (DIAS, 2004). Através dos diferentes fóruns e grupos de trabalhos, representados por 170 países, foram elaborados, além da Agenda 21, vários documentos como:

1. Convenção do Clima ou das Mudanças Climáticas;

2. Convenção da Biodiversidade;

3. Declaração de Princípios da Floresta;

4. Carta da Terra.

Observa-se que as discussões e os encontros/conferências acerca da Educação Ambiental, praticamente, iniciaram em 1975 e até os dias atuais continua sendo um debate em construção, uma vez que a Educação Ambiental é um conjunto de conteúdos e práticas ambientais orientadas para a resolução dos problemas concretos do ambiente, de forma interdisciplinar e de uma participação ativa e responsável de cada indivíduo da comunidade; de acordo 
com Dias (2004) a Educação Ambiental passou a ser um instrumento metodológico utilizado por diversos educadores.

\section{Contextualização da Educação Ambiental nas Universidades}

A Educação Ambiental é um relevante instrumento político que contribui para a emancipação do sujeito social na busca do estabelecimento de novas relações do homem com a natureza, que inclui a importância de se delinear um modelo de desenvolvimento sustentável contextualizado com a realidade e as demandas sociais. Silva (1998, p. 106) conceitua a Educação Ambiental como:

um processo de construção de conhecimento, baseado na afetividade e na solidariedade, e que a preservação da natureza é decorrência de uma identidade cultural com a terra que escolhemos para viver. E que esta identidade é conhecimento a ser construído (SILVA, 1998, p.106).

Educação Ambiental pode ser entendida também como um ramo da educação cujo objetivo é a disseminação do conhecimento sobre o ambiente, a fim de ajudar a sua preservação e utilização sustentável dos seus recursos. É uma metodologia de análise que surge a partir do crescente interesse do homem em assuntos como o ambiente, devido às grandes catástrofes naturais que têm assolado o mundo nas últimas décadas (GUIMARÃES et al., 2008).

Silva (2003) explicita que a Educação Ambiental tem um importante papel na busca por hábitos mais sustentáveis. A autora afirma que o ensino ambiental deve ser inserido de forma interdisciplinar e/ou transdisciplinar nas escolas, descartando as práticas tradicionais de ensino, em que os alunos ficam confinados no ambiente escolar juntamente com o professor que é tido como "detentor do saber", e os transformando em cidadãos capazes de agir de modo responsável e consciente, sabendo cumprir as suas obrigações, exigindo e respeitando os direitos próprios e os de toda uma comunidade.

Para que o educando compreenda e contextualize o ensino da Educação Ambiental é imprescindível, primeiramente, que o educador proporcione uma aproximação do alunado com as questões ambientais, que 0 mesmo não se delimite apenas na teoria. Em segundo plano, após o entrosamento, inicia-se as ações práticas de melhoria ao meio, incentivando-os em buscar possíveis soluções, a fim de minimizar os problemas ambientais.

Sobre o ensino a Lei 9.795 coloca em seus artigos $9^{\circ}$ e $10^{\circ}$ que:

Entende-se por Educação Ambiental na educação escolar a desenvolvida no âmbito dos currículos das instituições de ensino públicas e privada, englobando (...) II - educação superior. Art. 10 A Educação Ambiental será desenvolvida como uma prática educativa integrada, contínua e permanente em todos os níveis e modalidades de ensino formal. 
Com isso, e ainda de acordo com a lei, inciso $2^{\circ}$, nos cursos de pósgraduação, extensão e nas áreas voltadas ao aspecto metodológico da Educação Ambiental, quando se fizer necessário, é facultada a criação de disciplina específica, e sobre a formação de professores, a dimensão ambiental deverá constar nos currículos em todos os níveis e em todas as disciplinas.

De acordo com Abreu et al (2009), a Educação Ambiental pode ser indicada como um dos possíveis instrumentos interdisciplinares capaz de capacitar e, ao mesmo tempo, sensibilizar a população em geral acerca dos problemas ambientais nos quais se deparam a humanidade atualmente. Através desta, torna-se possível a elaboração de métodos e técnicas que facilitam a tomada de consciência das pessoas à respeito da gravidade e necessidade da implementação de providências urgentes sobre os problemas ambientais globais.

O momento atual necessita de ações efetivas que possibilite conservar e preservar o meio ambiente, precisa-se de estudos críticos com fundamentos teórico-metodológicos capazes de alterar a naturalização da realidade e, por fim, exige um professor diferenciado que seja educador, pesquisador, multiplicador e agente ambiental.

As universidades são espaços privilegiados na implementação de práticas educativas relativas à Educação Ambiental. Dias (2004) observa que, na escola, estão concentrados fatores que favorecem a organização e o desenvolvimento de atividades em sala de aula e atividades de campo, articuladas em processos participativos, implementados interdisciplinarmente, relacionadas às temáticas ambientais.

Um processo de Educação Ambiental bem-sucedido pode fomentar iniciativas que transcendam o ambiente escolar, atingindo tanto o bairro no qual a escola está inserida, como comunidades mais afastadas nas quais residam alunos, professores e funcionários; potenciais multiplicadores de informações e atividades relacionadas à EA. Entretanto, não raramente, a escola atua como mantenedora e reprodutora de uma cultura que é predatória ao ambiente, promovendo, ao mesmo tempo, atividades que remetem à sustentabilidade e outras incompatíveis com uma sociedade ambientalmente saudável (CHAPANI, 2001).

Nesse caso, as reflexões que dão início à implementação da Educação Ambiental no ensino formal devem contemplar aspectos que possam gerar alternativas para a superação desse quadro de modo a produzir consequências benéficas (ANDRADE, 2000). Cabe aos professores, por intermédio de prática interdisciplinar, proporem novas metodologias que favoreçam a inserção da Educação Ambiental (SATO, 2004).

Para que a EA tenha o êxito desejado, a comunidade escolar precisa desenvolver um sentido de participação e apropriação das mudanças e de seus resultados e, portanto, deve estar sob a responsabilidade de todos, inclusive dos discentes. Nas escolas a EA não tem como meta somente os alunos, mas também professores, diretores, funcionários, ou seja, toda a comunidade Revbea, São Paulo, V. 13, № 1: 87-107, 2018. 
escolar; essa característica - de estar sob a responsabilidade do próprio público a quem a EA se destina - pode representar mais um entrave em sua instrumentação (ANDRADE, 2000).

\section{Material e métodos}

A Universidade Federal de Campina Grande (UFCG), originada pelo desmembramento da Universidade Federal de Paraíba, foi criada pela Lei ำ 10.419 de 09 de Abril de 2002. Estende-se por sete campi localizados nos municípios de Pombal, Patos, Souza, Cajazeiras, Cuité, Sumé e Campina Grande, o último como campi sede.

Abaixo as Figuras 1 e 2 destacam, respectivamente, o mapa do Estado da Paraíba destacando os municípios que a UFCG possui campi localizados e, em seguida, o mapa da Universidade Federal de Campina Grande, campi sede localizado no município de Campina Grande - PB.

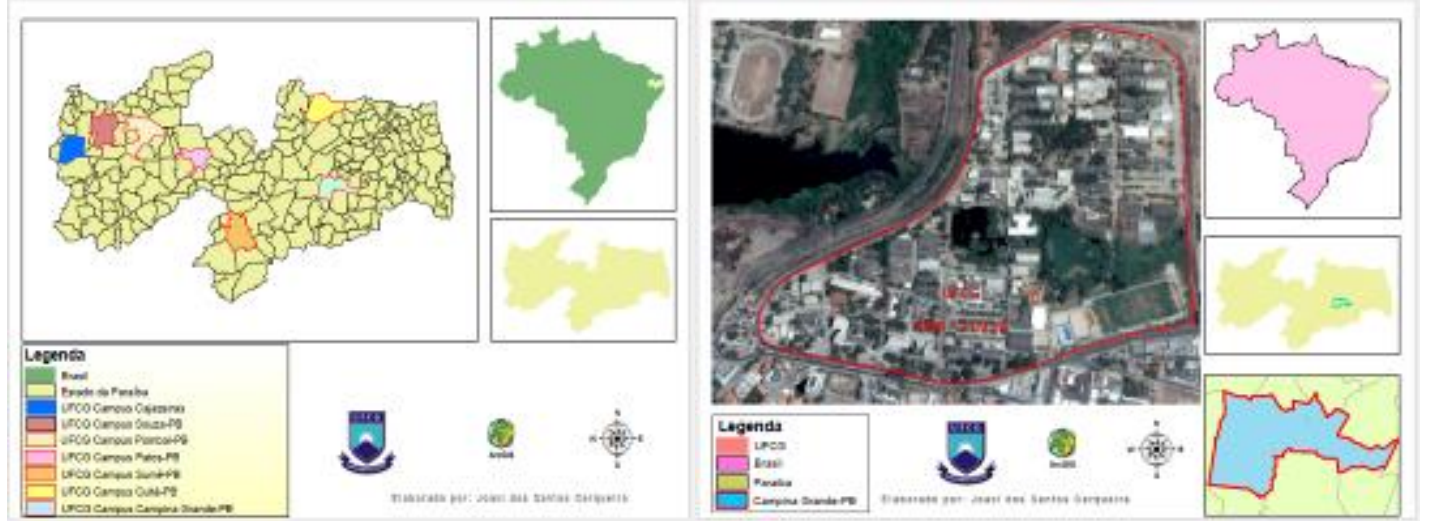

Figuras 1 e 2: Mapa do Estado da Paraíba com destaque dos municípios que possuem campi da UFCG e Mapa da Universidade Federal de Campina Grande, campi Campina Grande.

Fonte: CERQUEIRA, J.S (2015).

Mota (2012) relata um pouco do aspecto histórico da universidade:

Em 1952, foi criada a Escola Politécnica da Paraíba por Lei Estadual. Em 1953, a Escola Politécnica da Paraíba foi autorizada a funcionar. Em 1955, entrou em funcionamento a Escola Politécnica, pertencente à Universidade da Paraíba. Posteriormente, em 1960, foi transformada em Universidade Federal da Paraíba (UFPB), incorporando as estruturas universitárias existentes nas cidades de João Pessoa e Campina Grande. Em 1974 foi Criado o Centro de Ciência e Tecnologia, absorvendo a Escola Politécnica em Campina. Em 2002, pelo desmembramento da UFPB, foi criada a Universidade Federal de Campina Grande (UFCG), com sede em Campina Grande. Compõem ainda o universo dessa instituição seis outros campi localizados nas cidades de Patos, Sousa, Cajazeiras, Cuité, Pombal e Sumé, na região do Cariri Paraibano. 
Sendo considerada uma das universidades mais relevantes no Estado da Paraíba, dispõe dos seguintes dados quantitativos descritos na tabela abaixo (tabela 1).

Tabela 1: Universidade Federal de Campina Grande: Dados Quantitativos Gerais e do Campus de Campina Grande-2017.1.

\begin{tabular}{|c|c|c|}
\hline Descrição & Quantitativo & Campi Campina Grande \\
\hline Total de alunos matriculados & 14.968 & 7.230 \\
\hline Total de servidores técnicos-administrativos & 1.449 & 1.162 \\
\hline Total de docentes & 1.454 & 1.067 \\
\hline Total de campi & 07 & 01 \\
\hline Total de cursos de graduação & 105 & 21 \\
\hline Total de Cursos de Pós-Graduação & 30 & 54 \\
\hline
\end{tabular}

Fonte: Dados da Pesquisa, 2017.

Considerada como um Polo tecnológico da região Norte e Nordeste, a UFCG realiza importantes convênios com outras instituições de ensino, nacionais e internacionais. Mota (2012) destaca a parceria entre o Instituto Tecnológico da Aeronáutica (ITA), Projeto R.I.T.A. em 1964, com o governo americano, por intermédio da Universidade da Califórnia. Outros se sucederam, como os convênios com o Conselho Britânico, acordos de cooperação com agências, como a japonesa J.I.C.A., alemãs, holandesas, francesas, e um acordo de cooperação com a agência canadense C.I.D.A.

A fim de atender aos objetivos propostos desta pesquisa, utilizou-se a abordagem quantitativa para melhor esclarecer o objeto de estudo. Ocorrerão análises descritivas acerca dos documentos e projetos relacionados ao ensino, pesquisa e extensão da Universidade Federal de Campina Grande, o recorte temporal é entre os anos de 2002 a 2017, no entanto, justifica-se, primeiramente, que para o ensino (fluxogramas) utilizou-se o período de 2017.1, ano vigente da finalização da pesquisa.

No tocante aos projetos de pesquisa e extensão houve diferenciações, os dados para os projetos de pesquisa se deram no período entre 2002 a 2015, já para os projetos de extensão entre 2007 a 2014. Isso ocorreu devido a disponibilidade das informações, pois com o desmembramento das instituições Universidade Federal da Paraíba - UFPB da UFCG, alguns dados continuaram unificados, assim, impossibilitou a precisão das análises para a pesquisa.

A primeira etapa da pesquisa consistiu na realização da revisão da literatura, a qual, de acordo com Gil (2010), deve ser realizada a partir de 
consultas a materiais já elaborados, constituídos, principalmente, de livros, artigos de periódicos, bem como de materiais disponibilizados na Internet.

Assim, neste contexto, Silva e Menezes (2005) destacam que a partir da revisão da literatura é que se torna possível elaborar uma fundamentação teórica voltada para tratar o tema e o problema da pesquisa em questão, dando-se a possibilidade de se traçar um quadro teórico que resultará na estruturação conceitual que, por sua vez, dará sustentação ao desenvolvimento do estudo.

Posteriormente, a fim de atender os objetivos propostos, a segunda etapa da pesquisa consistiu em listar, analisar e destacar os 105 fluxogramas dos cursos de Graduação oferecidos na Universidade Federal de Campina Grande - UFCG, campi Campina Grande, observando disciplinas obrigatórias na grade curricular de formação que apresente a inserção da Educação Ambiental (Temática Ambiental).

Para análise dos documentos coletados foi utilizado o método de Laurence Bardin (2011), organizado em três etapas:

A pré-análise: realizamos a leitura geral, tendo em vista "a organização propriamente dita" do material coletado, em que organizamos as ideias iniciais que consideramos para realização da análise;

A exploração do material: realizamos a codificação e decomposição dos documentos;

O tratamento dos resultados: tratamos os resultados que estavam "brutos", tornando-os significativos para realização de inferências e interpretações. 2003.

Para elaboração dos gráficos e tabelas: uso do Microsoft Office Excel

Como terceira etapa da pesquisa, foram catalogados os projetos de pesquisa e extensão desenvolvidos na instituição no período entre 2007 a 2017, dados obtidos na Pró-Reitora de Pesquisa e Extensão da Universidade Federal de Campina Grande - UFCG.

Por fim, listou-se o quantitativo das dissertações e teses desenvolvidas na instituição que aborda a temática da Educação Ambiental no período entre 2007 a 2017.

\section{Resultados e discussão}

\section{Ensino}

A Universidade Federal de Campina Grande (UFCG) ofereceu o total de 105 cursos de Graduação no período 2017.1, distribuídos por seus 7 campi, no Estado da Paraíba (PB). No campus de Campina Grande são ofertados 54 cursos entre Licenciaturas, Bacharelados e Parfor (Plano Nacional de Formação de Professores da Educação Básica - modalidade presencial); 
campi Cajazeiras, 16 cursos; Sousa, total de 6 cursos; Patos, 5 cursos; 12 cursos em Cuité, 8 em Sumé e 4 cursos em Pombal.

Com a perspectiva de análise sobre o tema da pesquisa e Educação Ambiental (EA), foram listados, organizados e analisados os cursos que apresentam, na grade curricular obrigatória, disciplinas que se aproximam da temática relacionada à instrução ambiental.

Assim, com este objetivo, foram listados e analisados os fluxogramas de todos os cursos oferecidos na instituição, de todos os campi. Abaixo é apresentada a relação dos cursos analisados e aqueles que possuem disciplinas com aproximação à temática ambiental (Meio Ambiente e Educação Ambiental), o nome das disciplinas da sua grade obrigatória (Tabela 2).

Tabela 2: Relação dos cursos ofertados pela UFCG por Campis.

\begin{tabular}{|c|c|c|c|c|c|}
\hline № & Nome do curso & Modalidade & Turno & Campi & Disciplina \\
\hline 01 & ADMINISTRAÇÃO & Bacharelado & $\mathrm{D}$ & $\begin{array}{c}\text { Campina } \\
\text { Grande (CG) }\end{array}$ & - \\
\hline 02 & ADMINISTRAÇÃO & Bacharelado & $\mathrm{N}$ & $\mathrm{CG}$ & - \\
\hline 03 & $\begin{array}{l}\text { ARQUITETURA E } \\
\text { URBANISMO }\end{array}$ & Bacharelado & $\mathrm{D}$ & CG & $\begin{array}{l}\text { Conforto Ambiental e } \\
\text { Ciências do } \\
\text { Ambiente }\end{array}$ \\
\hline 04 & ARTE E MÍDIA & Bacharelado & $\mathrm{D}$ & $\mathrm{CG}$ & - \\
\hline 05 & $\begin{array}{l}\text { CIÊNCIA DA } \\
\text { COMPUTAÇÃO }\end{array}$ & Bacharelado & I & $\mathrm{CG}$ & - \\
\hline 06 & $\begin{array}{l}\text { CIÊNCIAS } \\
\text { ECONÔMICAS }\end{array}$ & Bacharelado & $\mathrm{D}$ & CG & - \\
\hline 07 & $\begin{array}{l}\text { CIÊNCIAS } \\
\text { ECONÔMICAS }\end{array}$ & Bacharelado & $\bar{N}$ & CG & - \\
\hline 08 & CIÊNCIAS SOCIAIS & Bacharelado & $\mathrm{D}$ & $\mathrm{CG}$ & - \\
\hline 09 & CIÊNCIAS SOCIAIS & Bacharelado & $\mathrm{N}$ & CG & - \\
\hline 10 & CIÊNCIAS SOCIAIS & Licenciatura & $\mathrm{N}$ & CG & - \\
\hline 11 & CIÊNCIAS SOCIAIS & Licenciatura & $\mathrm{D}$ & CG & - \\
\hline 12 & $\begin{array}{l}\text { COMUNICAÇÃO } \\
\text { SOCIAL }\end{array}$ & Bacharelado & $\mathrm{D}$ & CG & $\begin{array}{l}\text { Responsabilidade } \\
\text { socioambiental em } \\
\text { educomunicação }\end{array}$ \\
\hline 13 & $\begin{array}{l}\text { COMUNICAÇÃO } \\
\text { SOCIAL }\end{array}$ & Bacharelado & $\mathrm{N}$ & CG & $\begin{array}{l}\text { Responsabilidade } \\
\text { socioambiental em } \\
\text { educomunicação }\end{array}$ \\
\hline 14 & DESIGN & Bacharelado & $\mathrm{D}$ & $\mathrm{CG}$ & - \\
\hline 15 & ENFERMAGEM & Bacharelado & $\mathrm{D}$ & CG & - \\
\hline 16 & $\begin{array}{l}\text { ENGENHARIA } \\
\text { AGRÍCOLA }\end{array}$ & Bacharelado & $\mathrm{D}$ & CG & $\begin{array}{l}\text { Gestão ambiental; } \\
\text { Manejo de Recursos } \\
\text { Naturais; Poluição } \\
\text { Ambiental; Áreas } \\
\text { Degradadas e } \\
\text { Desastres } \\
\text { ambientais. }\end{array}$ \\
\hline 17 & ENGENHARIA CIVIL & Bacharelado & $\mathrm{D}$ & CG & - \\
\hline 18 & $\begin{array}{l}\text { ENGENHARIA DE } \\
\text { ALIMENTOS } \\
\end{array}$ & Bacharelado & D & CG & - \\
\hline 19 & $\begin{array}{l}\text { ENGENHARIA DE } \\
\text { MATERIAIS }\end{array}$ & Bacharelado & $\mathrm{D}$ & $\mathrm{CG}$ & $\begin{array}{l}\text { Reciclagem de } \\
\text { Materiais e Ciências } \\
\text { do Ambiente }\end{array}$ \\
\hline 20 & $\begin{array}{l}\text { ENGENHARIA DE } \\
\text { MINAS }\end{array}$ & Bacharelado & $\mathrm{D}$ & $\mathrm{CG}$ & - \\
\hline
\end{tabular}


...continuação.

\begin{tabular}{|c|c|c|c|c|c|}
\hline 21 & $\begin{array}{l}\text { ENGENHARIA DE } \\
\text { PETRÓLEO }\end{array}$ & Bacharelado & $\mathrm{D}$ & CG & - \\
\hline 22 & $\begin{array}{l}\text { ENGENHARIA DE } \\
\text { PRODUÇÃO }\end{array}$ & Bacharelado & $\mathrm{D}$ & CG & - \\
\hline 23 & $\begin{array}{l}\text { ENGENHARARIA } \\
\text { ELÉTRICA }\end{array}$ & Bacharelado & $\mathrm{D}$ & CG & - \\
\hline 24 & $\begin{array}{l}\text { ENGENHARIA } \\
\text { MECÂNICA }\end{array}$ & Bacharelado & $\mathrm{D}$ & CG & - \\
\hline 25 & $\begin{array}{l}\text { ENGENHARIA } \\
\text { QUIIMICA }\end{array}$ & Bacharelado & $\mathrm{D}$ & $\overline{C G}$ & Gestão Ambiental \\
\hline 26 & ESTATISTTICA & Bacharelado & $\mathrm{D}$ & CG & - \\
\hline 27 & FILOSOFIA & Bacharelado & $\mathrm{N}$ & CG & - \\
\hline 28 & FILOSOFIA & Licenciatura & $\mathrm{N}$ & CG & - \\
\hline 29 & FISICA & Bacharelado & $\mathrm{D}$ & CG & - \\
\hline 30 & FÍSICA & Bacharelado & $\mathrm{D}$ & CG & - \\
\hline 31 & GEOGRAFIA & Licenciatura & $\mathrm{N}$ & CG & - \\
\hline 32 & GEOGRAFIA & Licenciatura & $\mathrm{D}$ & CG & - \\
\hline 33 & HISTÓRIA & Licenciatura & $\mathrm{N}$ & $\mathrm{CG}$ & - \\
\hline 34 & HISTÓRIA & Licenciatura & $\mathrm{D}$ & CG & - \\
\hline 35 & HISTÓRIA & Licenciatura & $\mathrm{V}$ & CG & - \\
\hline 36 & LETRAS - ESPANHOL & Licenciatura & $\mathrm{N}$ & CG & - \\
\hline 37 & LETRAS - LIBRAS & Licenciatura & $\mathrm{D}$ & CG & - \\
\hline 38 & $\begin{array}{l}\text { LETRAS - } \\
\text { LIING.PORT./LÍNG.FRA } \\
\text { NC }\end{array}$ & Licenciatura & $\mathrm{D}$ & CG & - \\
\hline 39 & $\begin{array}{l}\text { LETRAS - LÍNGUA E } \\
\text { LIT. PORTUGUESA }\end{array}$ & Licenciatura & $\mathrm{N}$ & CG & - \\
\hline 40 & $\begin{array}{l}\text { LETRAS - LÍNGUA } \\
\text { INGLESA }\end{array}$ & Licenciatura & $\mathrm{D}$ & CG & - \\
\hline 41 & $\begin{array}{l}\text { LETRAS - LÍNGUA } \\
\text { PORTUGUESA }\end{array}$ & Licenciatura & $\mathrm{N}$ & CG & - \\
\hline 42 & $\begin{array}{l}\text { LETRAS - LÍNGUA } \\
\text { PORTUGUESA }\end{array}$ & Licenciatura & $\mathrm{D}$ & CG & - \\
\hline 43 & MATEMÁTICA & Licenciatura & $\mathrm{D}$ & CG & - \\
\hline 44 & MATEMÁTICA & Licenciatura & $\mathrm{V}$ & $\mathrm{CG}$ & - \\
\hline 45 & MATEMÁTICA & Licenciatura & $\mathrm{N}$ & CG & - \\
\hline 46 & MATEMÁTICA & Bacharelado & $\mathrm{D}$ & CG & - \\
\hline 47 & MEDICINA & Bacharelado & $\mathrm{D}$ & CG & - \\
\hline 48 & METEOROLOGIA & Bacharelado & $\mathrm{D}$ & CG & Poluição atmosférica \\
\hline 49 & MÚSICA & Bacharelado & $\mathrm{D}$ & CG & - \\
\hline 50 & MÚSICA & Licenciatura & $\mathrm{D}$ & CG & - \\
\hline 51 & PEDAGOGIA & Licenciatura & $\mathrm{D}$ & $\mathrm{CG}$ & - \\
\hline 52 & PEDAGOGIA & Licenciatura & $\mathrm{N}$ & CG & - \\
\hline 53 & PSICOLOGIA & Bacharelado & $\mathrm{N}$ & CG & - \\
\hline 54 & PSICOLOGIA & Bacharelado & $\mathrm{D}$ & CG & - \\
\hline 55 & $\begin{array}{l}\text { CIÉNCIAS } \\
\text { BIOLÓGICAS }\end{array}$ & Licenciatura & $\mathrm{D}$ & Cajazeiras & - \\
\hline 56 & ENFERMAGEM & Bacharelado & $\mathrm{D}$ & Cajazeiras & - \\
\hline 57 & FÍSICA & Licenciatura & $\mathrm{N}$ & Cajazeiras & - \\
\hline 58 & GEOGRAFIA & Licenciatura & $\bar{D}$ & Cajazeiras & - \\
\hline 59 & GEOGRAFIA & Licenciatura & $\mathrm{N}$ & Cajazeiras & - \\
\hline 60 & HISTÓRIA & Licenciatura & $\mathrm{D}$ & Cajazeiras & - \\
\hline 61 & HISTÓRIA & Licenciatura & $\mathrm{N}$ & Cajazeiras & - \\
\hline 62 & $\begin{array}{l}\text { LETRAS - LÍNGUA } \\
\text { INGLESA }\end{array}$ & Licenciatura & $\mathrm{D}$ & Cajazeiras & - \\
\hline 63 & $\begin{array}{l}\text { LETRAS - LÍNGUA } \\
\text { PORTUGUESA }\end{array}$ & Licenciatura & $\mathrm{D}$ & Cajazeiras & - \\
\hline
\end{tabular}

Continua...

Revbea, São Paulo, V. 13, № 1: 87-107, 2018. 
...continuação.

\begin{tabular}{|c|c|c|c|c|c|}
\hline 64 & $\begin{array}{l}\text { LETRAS - LÍNGUA } \\
\text { PORTUGUESA }\end{array}$ & Licenciatura & $\mathrm{D}$ & Cajazeiras & - \\
\hline 65 & MATEMÁTICA & Licenciatura & $\mathrm{D}$ & Cajazeiras & - \\
\hline 66 & MEDICINA & Bacharelado & D & Cajazeiras & - \\
\hline 67 & PEDAGOGIA & Licenciatura & $\mathrm{D}$ & Cajazeiras & - \\
\hline 68 & PEDAGOGIA & Licenciatura & $\mathrm{N}$ & Cajazeiras & - \\
\hline 69 & QUÍMICA & Licenciatura & $\mathrm{N}$ & Cajazeiras & - \\
\hline 70 & QUÍMICA (PARFOR) & Licenciatura & $\mathrm{N}$ & Cajazeiras & - \\
\hline 71 & ADMINISTRAÇÃO & Bacharelado & $\mathrm{N}$ & Sousa & - \\
\hline 72 & CIÊNCIAS CONTÁBEIS & Bacharelado & $\mathrm{N}$ & Sousa & $\begin{array}{l}\text { Contabilidade e } \\
\text { Educação Ambiental }\end{array}$ \\
\hline 73 & DIREITO & Bacharelado & $\mathrm{D}$ & Sousa & - \\
\hline 74 & DIREITO & Bacharelado & $\mathrm{N}$ & Sousa & - \\
\hline 75 & DIREITO & Bacharelado & $\mathrm{V}$ & Sousa & - \\
\hline 76 & SERVIÇO SOCIAL & Licenciatura & $\mathrm{D}$ & Sousa & - \\
\hline 77 & $\begin{array}{l}\text { CIÊNCIAS } \\
\text { BIOLÓGICAS }\end{array}$ & Licenciatura & $\mathrm{D}$ & Patos & - \\
\hline 78 & $\begin{array}{l}\text { CIÊNCIAS } \\
\text { BIOLÓGICAS }\end{array}$ & Licenciatura & $\mathrm{N}$ & Patos & - \\
\hline 79 & $\begin{array}{l}\text { ENGENHARIA } \\
\text { FLORESTAL }\end{array}$ & Bacharelado & $\mathrm{D}$ & Patos & $\begin{array}{l}\text { Ecologia, } \\
\text { Recuperação de } \\
\text { áreas degradadas, } \\
\text { Manejo e } \\
\text { conservação do solo, } \\
\text { e Política e } \\
\text { Legislação Ambiental }\end{array}$ \\
\hline 80 & $\begin{array}{l}\text { MEDICINA } \\
\text { VETERINÁRIA }\end{array}$ & Bacharelado & $\mathrm{D}$ & Patos & Ecologia \\
\hline 81 & ODONTOLOGIA & Bacharelado & $\mathrm{D}$ & Patos & - \\
\hline 82 & $\begin{array}{l}\text { CIÊNCIAS } \\
\text { BIOLÓGICAS }\end{array}$ & Licenciatura & $\mathrm{D}$ & Cuité & $\begin{array}{l}\text { Meio ambiente físico } \\
\text { e } \\
\text { Ecossistemas/Ecolog } \\
\text { ia } \\
\text { Ecologia Geral e } \\
\text { Planejamento em } \\
\text { educação }\end{array}$ \\
\hline 83 & $\begin{array}{l}\text { CIÊNCIAS } \\
\text { BIOLÓGICAS }\end{array}$ & Licenciatura & $\mathrm{N}$ & Cuité & $\begin{array}{l}\text { Meio ambiente físico } \\
\text { e Ecos- } \\
\text { sistemas/Ecologia } \\
\text { Ecologia Geral e } \\
\text { Planejamento em } \\
\text { educação }\end{array}$ \\
\hline 84 & ENFERMAGEM & Bacharelado & $\mathrm{D}$ & Cuité & $\begin{array}{l}\text { Saúde ambiental e } \\
\text { educação em saúde }\end{array}$ \\
\hline 85 & FARMÁCIA & Bacharelado & $\mathrm{D}$ & Cuité & - \\
\hline 86 & FÍSICA & Licenciatura & $\mathrm{D}$ & Cuité & - \\
\hline 87 & FÍSICA & Licenciatura & $\mathrm{N}$ & Cuité & - \\
\hline 88 & MATEMÁTICA & Licenciatura & $\mathrm{D}$ & Cuité & - \\
\hline 89 & MATEMÁTICA & Licenciatura & $\mathrm{N}$ & Cuité & - \\
\hline 90 & NUTRIÇÃO & Bacharelado & $\mathrm{D}$ & Cuité & - \\
\hline 91 & NUTRIÇÃO & Bacharelado & $\mathrm{N}$ & Cuité & - \\
\hline 92 & QUÍMICA & Licenciatura & $\mathrm{D}$ & Cuité & Química Ambiental \\
\hline 93 & QUÍMICA & Licenciatura & $\mathrm{N}$ & Cuité & Química Ambiental \\
\hline 94 & CIÊNCIAS SOCIAIS & Licenciatura & $M$ & Sumé & - \\
\hline 95 & $\begin{array}{l}\text { ENG. DE } \\
\text { BIOTECNOLOGIA E } \\
\text { BIOPROCESSOS }\end{array}$ & Bacharelado & $\mathrm{D}$ & Sumé & - \\
\hline
\end{tabular}


...continuação.

\begin{tabular}{|c|c|c|c|c|c|}
\hline 96 & $\begin{array}{l}\text { ENGENHARIA DE } \\
\text { BIOSSISTEMAS }\end{array}$ & Bacharelado & $\mathrm{D}$ & Sumé & $\begin{array}{l}\text { Gestão Ambiental e } \\
\text { Ciências do ambiente }\end{array}$ \\
\hline 97 & $\begin{array}{l}\text { ENGENHARIA DE } \\
\text { PRODUÇÃO }\end{array}$ & Bacharelado & $\mathrm{D}$ & Sumé & Gestão Ambiental \\
\hline 98 & $\begin{array}{l}\text { INTERDISCIPLINAR EM } \\
\text { EDUC. DO CAMPO }\end{array}$ & Licenciatura & $\mathrm{D}$ & Sumé & - \\
\hline 99 & AGROECOLOGIA & Tecnólogo & $\mathrm{D}$ & Sumé & - \\
\hline 100 & GESTÃO PÚBLICA & Tecnólogo & $\mathrm{N}$ & Sumé & - \\
\hline 101 & AGRONOMIA & Bacharelado & $\mathrm{D}$ & Pombal & - \\
\hline 102 & $\begin{array}{l}\text { ENGENHARIA } \\
\text { AMBIENTAL }\end{array}$ & Bacharelado & D & Pombal & $\begin{array}{l}\text { Princípios e } \\
\text { Estratégias da } \\
\text { Educação Ambiental, } \\
\text { Ecologia Geral, } \\
\text { Introdução a } \\
\text { Engenharia } \\
\text { Sustentável, Poluição } \\
\text { atmosférica, } \\
\text { Economia ambiental, } \\
\text { Gestão ambiental, } \\
\text { Recursos Naturais e } \\
\text { Energias } \\
\text { Renováveis, } \\
\text { Gerenciamento de } \\
\text { Resíduos Sólidos; } \\
\text { Legislação e Direito } \\
\text { Ambiental e } \\
\text { Avaliação de } \\
\text { Impactos Ambientais. }\end{array}$ \\
\hline 103 & ENGENHARIA CIVIL & Bacharelado & $\mathrm{D}$ & Pombal & - \\
\hline 104 & $\begin{array}{l}\text { ENGENHARIA DE } \\
\text { ALIMENTOS }\end{array}$ & Bacharelado & $\mathrm{D}$ & Pombal & $\begin{array}{l}\text { Princípios e } \\
\text { Estratégias da e } \\
\text { Educação Ambiental }\end{array}$ \\
\hline 105 & $\begin{array}{l}\text { ENGENHARIA DE } \\
\text { ALIMENTOS }\end{array}$ & Bacharelado & $\mathrm{D}$ & Pombal & - \\
\hline
\end{tabular}

Fonte: Dados da Pesquisa, 2017.

Neste sentido Silva (2007, p. 144-149) destaca a urgência de uma "universidade ambientalmente responsável", torna-se preocupante a lentidão com que essas instituições superiores têm aderido à inserção da Educação Ambiental nos cursos superiores. O autor destaca que mesmo com tímidas iniciativas, são necessárias uma maior integração e sistematização das informações nesse campo.

A Política Nacional de EA - PNEA, Lei 9.795/99, regulamentada em 2002, consolida a EA no Brasil como "um componente essencial e permanente da educação nacional" e propõe (Art. $8^{\circ}, \S 2^{\circ}$, inciso II), que a capacitação de recursos humanos deve voltar-se para "a incorporação da dimensão ambiental na formação, especialização e atualização dos educadores de todos os níveis e modalidades de ensino". "No Art. $9^{\circ}$ se refere à EA no contexto escolar como aquela "desenvolvida no âmbito dos currículos das instituições de ensino públicas e privada", englobando a educação básica, a educação superior e a educação especial, profissional e de jovens e adultos". 
O Art. 10 determina que "a Educação Ambiental será desenvolvida como uma prática educativa integrada, contínua e permanente em todos os níveis e modalidades do ensino formal". Já o Art. 11 determina que "a dimensão ambiental deve constar dos currículos de formação de professores, em todos os níveis e em todas as disciplinas" (BRASIL, Lei $n^{\circ}$ 9.795/99. In: PRONEA, 2005, p.68).

Com isso, observa-se que no tocante ao ensino na Universidade Federal de Campina Grande, apenas $9,26 \%$ dos cursos oferecidos na instituição atentem à Política Nacional de Educação Ambiental, em que preconiza que a Educação Ambiental é fundamental para uma sensibilização das pessoas em relação ao mundo em que vivem, para que possam ter cada vez mais qualidade de vida, sem desrespeitar o meio ambiente. Conforme estabelecido em lei, a PNEA deve ser tratada de forma interdisciplinar, articulada, em todos os níveis de ensino e não de forma isolada como uma disciplina. instituição.

Exemplos de alguns documentos analisados obtidos no site da

\begin{tabular}{|c|c|c|c|c|c|c|c|c|}
\hline$\equiv \equiv$ & sos UFC & Arquitetc & e Urbanismo & & & $C G, C$ & & \\
\hline $1^{\circ}$ Período & $2^{2}$ Período & $3^{\circ}$ Período & $4^{\circ}$ Período & $5^{\circ}$ Período & $6^{\circ}$ Período & $7^{\circ}$ Período & $8^{\circ}$ Período & 90 Período \\
\hline $\begin{array}{l}\text { Geometria } \\
\text { Descritivo }\end{array}$ & $\begin{array}{l}\text { Introducão o } \\
\text { Arquitetura }\end{array}$ & $\begin{array}{l}\text { Conforto } \\
\text { Ambiental| }\end{array}$ & $\begin{array}{l}\text { Teoria e Hist. da } \\
\text { Arq. e do Uro. } \|\end{array}$ & $\begin{array}{l}\text { Teoria e Hist. da } \\
\text { Ara. e do Urb. III }\end{array}$ & $\begin{array}{l}\text { Teoria e Hist. da } \\
\text { Arq. e do Urb. IV }\end{array}$ & $\begin{array}{l}\text { Teoria e Hist. da } \\
\text { Arq. e do Urb. V }\end{array}$ & $\begin{array}{l}\text { Desenho de } \\
\text { Detalhes } \\
\text { Construtivos }\end{array}$ & $\begin{array}{l}\text { Tecnologia do } \\
\text { Ambiente } \\
\text { Construido }\end{array}$ \\
\hline $\begin{array}{l}\text { Cálculo } \\
\text { Diferenciale } \\
\text { Integral| }\end{array}$ & $\begin{array}{l}\text { Fund do } \\
\text { Planejamentoe } \\
\text { do Uesenho } \\
\text { Urbano }\end{array}$ & $\begin{array}{l}\text { Estudos Urbanos e } \\
\text { Regionais I }\end{array}$ & $\begin{array}{l}\text { Projeto Assistido } \\
\text { Por Computador II }\end{array}$ & $\begin{array}{l}\text { Projeto de } \\
\text { Arquitetura III }\end{array}$ & $\begin{array}{l}\text { Projeto de } \\
\text { Arquitetura IV }\end{array}$ & $\begin{array}{l}\text { Geotecnologios } \\
\text { Aplicadas }\end{array}$ & $\begin{array}{l}\text { Projeto de } \\
\text { Arquitetura VI }\end{array}$ & $\begin{array}{l}\text { Atelier Integ de } \\
\text { Ara, Urb e } \\
\text { Paisagismo }\end{array}$ \\
\hline $\begin{array}{l}\text { Espaco, Forma e } \\
\text { Plastica }\end{array}$ & $\begin{array}{c}\text { Estética e História } \\
\text { dos Artes } \|\end{array}$ & $\begin{array}{l}\text { Projeto Assistido } \\
\text { Por Computador I }\end{array}$ & $\begin{array}{l}\text { Projeto de } \\
\text { Aravitetura ll }\end{array}$ & $\begin{array}{l}\text { Estudos Urbanos e } \\
\text { Regionais III }\end{array}$ & $\begin{array}{l}\text { Estudos Urbanos e } \\
\text { Regioncis IV }\end{array}$ & $\begin{array}{l}\text { Projeto de } \\
\text { Arquitetura V }\end{array}$ & $\begin{array}{l}\text { Pesq Cient em } \\
\text { Arq, Urban e } \\
\text { Paisagismo }\end{array}$ & $\begin{array}{l}\text { Introdução ao } \\
\text { Trabalho de } \\
\text { Conclusão do C }\end{array}$ \\
\hline $\begin{array}{l}\text { Estéticica e História } \\
\text { dos Artes I }\end{array}$ & $\begin{array}{l}\text { Desenho Técnico } \\
\text { A Arquitetônnico }\end{array}$ & $\begin{array}{l}\text { Projeto de } \\
\text { Arguitetural }\end{array}$ & $\begin{array}{l}\text { Estudos Urbanos e } \\
\text { Regionais II }\end{array}$ & $\begin{array}{l}\text { Planejamento da } \\
\text { Paisagem II }\end{array}$ & $\begin{array}{l}\text { Instalacoes } \\
\text { Prediais II }\end{array}$ & $\begin{array}{l}\text { Estudos Utranosose } \\
\text { Regionais V }\end{array}$ & $\begin{array}{l}\text { Tecnologias } \\
\text { Socioiis }\end{array}$ & \\
\hline $\begin{array}{l}\text { Estudos } \\
\text { Socioeconomicos }\end{array}$ & $\begin{array}{l}\text { Materiais de } \\
\text { Construçäol }\end{array}$ & $\begin{array}{c}\text { Sistemas Estruturais } \\
\end{array}$ & $\begin{array}{l}\text { Planejamento da } \\
\text { Paisogem I }\end{array}$ & $\begin{array}{l}\text { Instalacoes } \\
\text { Prediois! }\end{array}$ & $\begin{array}{l}\text { Conforto } \\
\text { Ambiental III }\end{array}$ & & & \\
\hline Desenho Artistico & Física Geral II & $\begin{array}{l}\text { Teoria e Hist. da } \\
\text { Arq. e do Urb. I }\end{array}$ & $\begin{array}{c}\text { Sistemas Estruturais } \\
\|\end{array}$ & $\begin{array}{l}\text { Ciencias do } \\
\text { Ambiente }\end{array}$ & & & & \\
\hline
\end{tabular}

Fluxograma 1: Curso de Arquitetura e Urbanismo

Fonte: Dados da pesquisa, site http://pre.ufcg.edu.br/pre/graduacao-na-ufcg, 2017.1.

O curso de Arquitetura e Urbanismo, campi Campina Grande, apresenta disciplinas cujos títulos são "Conforto Ambiental" e "Ciências do Ambiente", estas disciplinas obrigatórias do curso abordam, de forma tímida, o Meio Ambiente e suas relações com a sociedade, assim, obedecem à Política Nacional que, na seção II da lei apresenta: "entende-se por Educação Ambiental na educação escolar aquela desenvolvida no âmbito dos currículos das instituições de ensino públicas e privadas". 
O curso de Comunicação Social oferece a disciplina "Responsabilidade Socioambiental em Educomunicação", nesta perspectiva, pode-se observar que mesmo possuindo apenas uma disciplina obrigatória, contempla a lei na seção I inciso 3 quanto das ações de estudos, pesquisas e experimentações, parágrafo II - "a difusão de conhecimentos, tecnologias e informações sobre a questão ambiental".

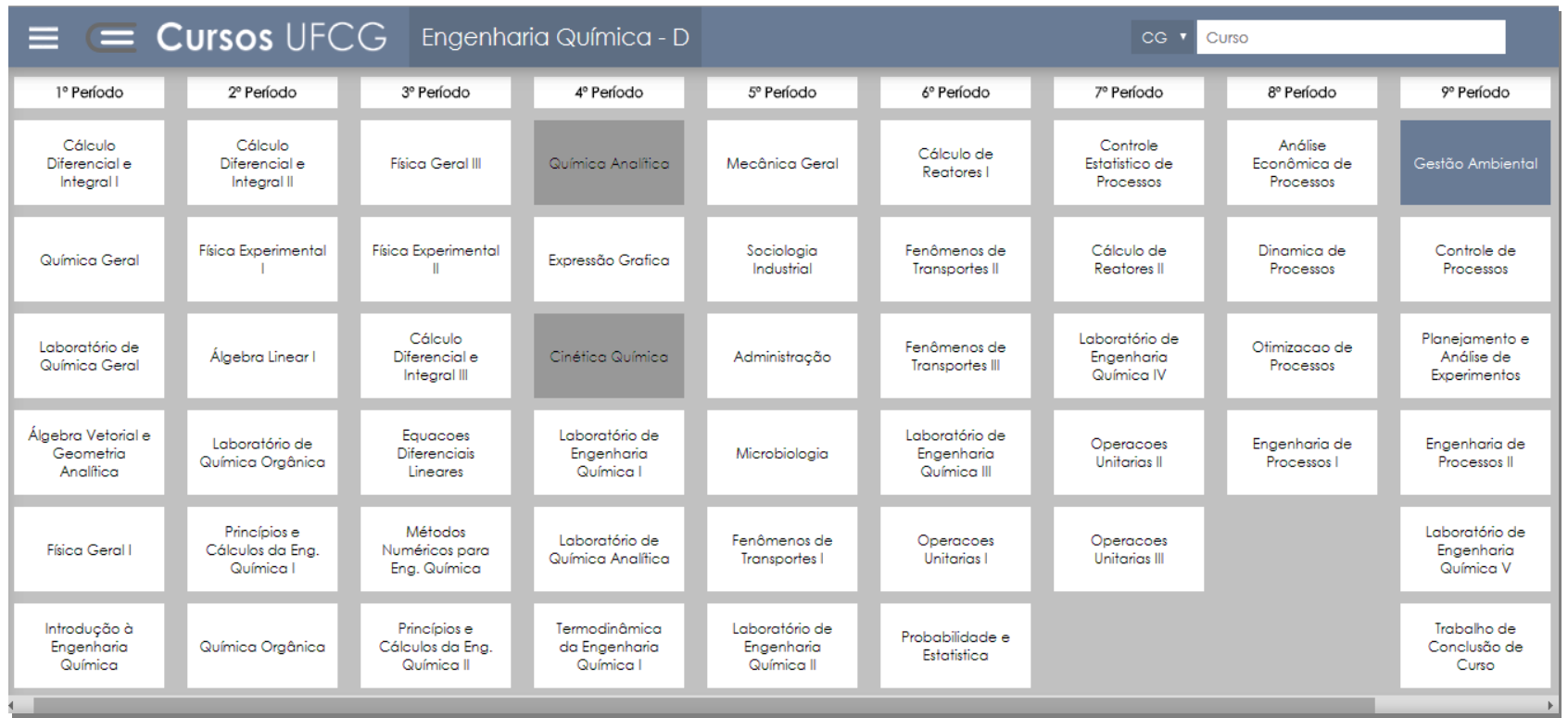

Fluxograma 2: Engenharia Química

Fonte: Dados da pesquisa, site http://pre.ufcg.edu.br/pre/graduacao-na-ufcg , 2017.1

A presença da disciplina de "Gestão Ambiental" no curso de Engenharia Química, na Universidade Federal de Campina Grande, corrobora o que regulamenta a Política Nacional no tocante à dimensão ambiental, que deve ser repassada, de forma interdisciplinar, em diferentes modalidades e níveis de ensino.

\section{Projetos de Extensão}

No tocante à análise do quantitativo e qualitativo dos projetos de extensão na Universidade Federal de Campina Grande - UFCG sobre a abordagem da Educação Ambiental, o gráfico 01 apresenta o número total de publicação pela Pró-Reitoria de Pesquisa e Extensão (PROPEX), no período de 2007 a 2017, em paralelo ao quantitativo de trabalho que contemplam a PNEA. Apenas (13\% dos trabalhos) preconizam a Política Nacional de Educação Ambiental, direta e indiretamente, distribuídos em doze categorias. Ressalta-se que dos trabalhos que abordam a Lei 9795/1999 30\% estão concentrados na categoria de Meio Ambiente.

Abaixo a lista com as categorias dos projetos (Tabela 3). 
Tabela 3: Relação das categorias dos Projetos de Extensão na Universidade Federal de Campina Grande - PB (Campus sede).

\begin{tabular}{|l|}
\hline \multicolumn{1}{|c|}{ CATEGORIAS } \\
\hline Comunicação, Cultura e Educação. \\
\hline Direito \\
\hline Meio ambiente \\
\hline Saúde \\
\hline Tecnologia \\
\hline Saneamento ambiental \\
\hline Engenharia de água e solo \\
\hline Recursos Hídricos \\
\hline Tecnologias e utilização de produtos florestais \\
\hline Manejo florestal \\
\hline Energia da biomassa \\
\hline Conservação da natureza \\
\hline
\end{tabular}

Fonte: Dados da Pesquisa, 2017.

Conforme distribuição, no gráfico, os maiores percentuais dos trabalhos que abordam a temática ambiental encontram-se nas áreas de Meio ambiente, como já mencionado, Engenharia de Água e Solo com (16\% dos trabalhos), Comunicação, Cultura e Educação com (11\% dos trabalhos) e Saúde com $(9,68 \%$ dos trabalhos). Vale salientar, que do número total de trabalhos que tratam da EA desenvolvidos nesta instituição, apenas (11,29\% dos trabalhos) têm continuidade com novos pesquisadores, novos títulos; porém, com a mesma temática. São números relativamente bons e, a partir dessa realidade, pode-se observar a importância e relevância da pesquisa que servirá de base para o direcionamento de estudos futuros (Figura 3).

\section{Total de projetos de extensão e os que preconizam PNEA - 2007 a 2014: Campi Campina Grande:}

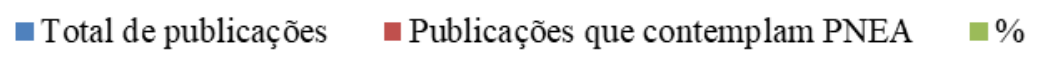

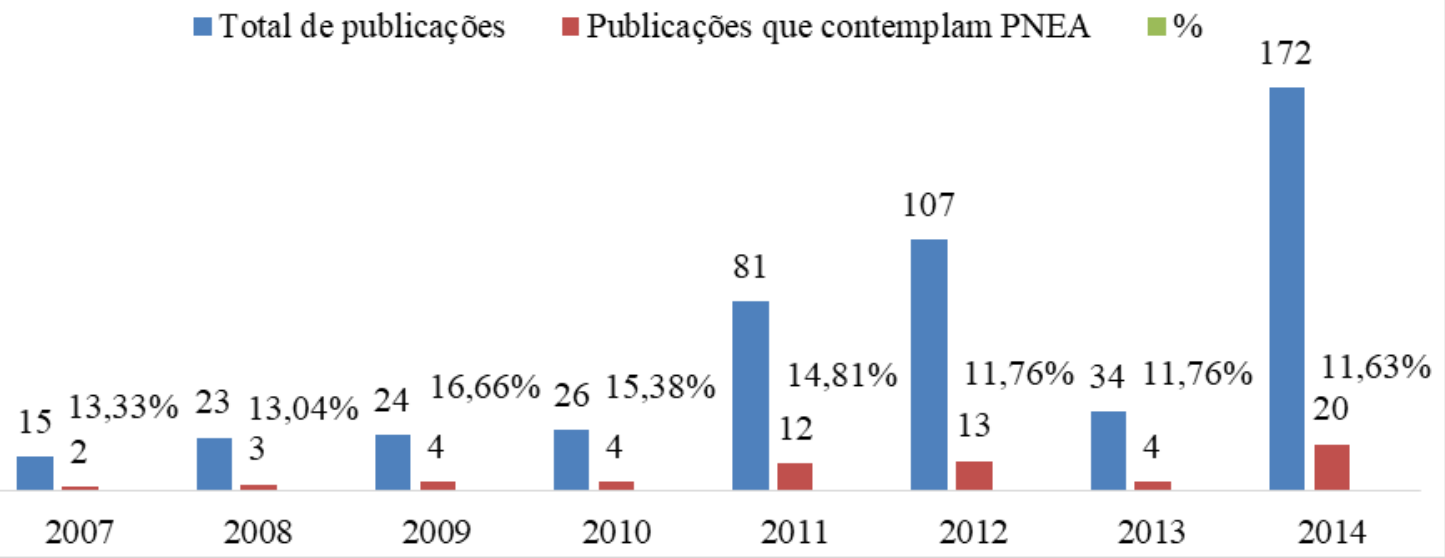

Figura 3: Campi Campina Grande: Total de projetos de extensão que preconizam PNEA de 2007 a 2014. Fonte: Dados da pesquisa, 2017.

Revbea, São Paulo, V. 13, № 1: 87-107, 2018. 
As extensões universitárias possibilitam aos alunos graduandos o estudo e a compreensão dos fatores econômicos, sociais, políticos, tecnológicos e ambientais, cada vez mais, junto à sociedade, ou seja, possibilitam uma troca de valores entre a universidade e o meio. Cabe à instituição planejar e executar atividades que não violem a cultura dessas comunidades.

$\mathrm{Na}$ Figura 4, verificam-se as categorias das publicações dos projetos de extensão realizadas na UFCG, que são as seguintes: Comunicação, Cultura e Educação; Direito; Meio Ambiente; Saúde; Tecnologia; Saneamento Ambiental; Engenharia de água e solo; Recursos Hídricos; Tecnologias e utilização de produtos florestais; manejo florestal; Energia da biomassa e Conservação de natureza.

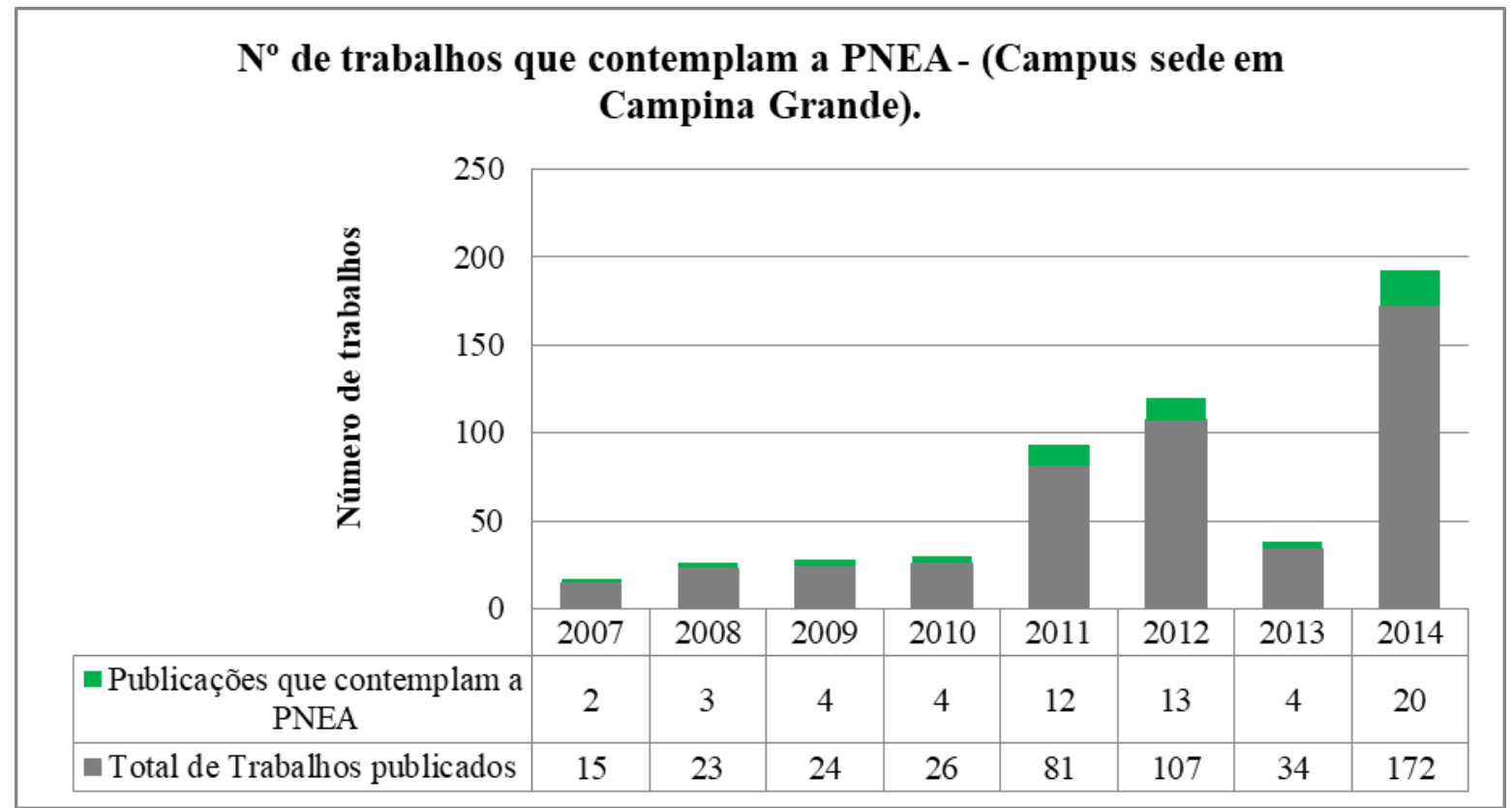

Figura 4: Distribuição total de publicações por ano que preconizam a PNEA na Universidade Federal de Campina Grande - PB nos projetos de extensão - 2007-2014.

Fonte: Dados da Pesquisa, 2017.

Podemos observar que quando o ensino apresenta falhas e lacunas de conteúdo obrigatório, consequentemente, os outros espaços de aprendizagem não são satisfatórios, em um universo de 360 projetos de extensão, durante o período de 2011 a 2014, apenas 49 trabalhos contemplaram de alguma forma, direta ou indiretamente, a temática Meio Ambiente. Esse dado é preocupante, uma vez que, a universidade ainda nos dias atuais não assumiu sua responsabilidade ambiental que seria, no mínimo, institucionalizar a dimensão ambiental na instituição.

O Estatuto da UFCG, documento com 59 páginas aprovado pelo Conselho Universitário da Universidade Federal de Campina Grande, em 03 de Outubro de 2002, apresenta apenas o termo "meio ambiente" no Art. 11, inciso IV, que estabelece como um dos princípios "promover a paz, a solidariedade, a defesa dos direitos humanos e a preservação do meio ambiente". 


\section{Pesquisa}

Em uma análise do material disponível: biblioteca da instituição, banco de teses e dissertações, e sites dos programas de pós-graduação; a UFCG se destaca no quantitativo de dissertações que equivale, aproximadamente, menos de $3 \%$ dos trabalhos publicados anualmente, aborda a PNEA. Além disso, os temas centrais dos trabalhos estão na área das Engenharias Agrícola e Materiais e, sendo mais específico, o tema abordado é a "produção de culturas de forma sustentável".

De acordo com a pesquisa apresentam-se os seguintes dados.

Tabela 4: Quantitativo de dissertações e teses que abordam a PNEA.

\begin{tabular}{|c|c|c|c|c|}
\hline $\begin{array}{c}\text { Ano de } \\
\text { Publicação }\end{array}$ & $\begin{array}{c}\text { Total de } \\
\text { dissertações }\end{array}$ & $\begin{array}{c}\text { No de } \\
\text { dissertações } \\
\text { que tratam } \\
\text { PNEA }\end{array}$ & Total de teses & $\begin{array}{c}\text { No de teses que } \\
\text { tratam PNEA }\end{array}$ \\
\hline 2002 & 187 & 6 & 29 & 3 \\
\hline 2003 & 155 & 3 & 28 & 4 \\
\hline 2004 & 138 & 1 & 39 & 5 \\
\hline 2005 & 142 & 3 & 34 & 1 \\
\hline 2006 & 154 & 4 & 55 & 1 \\
\hline 2007 & 175 & 5 & 59 & 4 \\
\hline 2008 & 189 & 7 & 63 & 5 \\
\hline 2009 & 220 & 8 & 78 & 4 \\
\hline 2010 & 224 & 6 & 70 & 8 \\
\hline 2011 & 255 & 1 & 110 & 7 \\
\hline 2012 & 226 & 5 & 107 & 4 \\
\hline 2013 & 227 & 4 & 115 & 2 \\
\hline 2014 & 216 & 3 & 87 & 4 \\
\hline 2015 & 173 & 6 & 85 & 60 \\
\hline Total & 2681 & 60 & 959 & \\
\hline
\end{tabular}

Fonte: Dados da Pesquisa, 2017.

Contudo, o que se pode destacar é que de aproximadamente 2700 dissertações, apenas 3 trabalhos preconizam diretamente, conforme estabelecido na lei, a abordagem de Educação Ambiental, assim, torna-se ínfimo. Na análise das teses, no total de 959 trabalhos publicados 10\% abordam direta ou indiretamente o PNEA. O gráfico abaixo apresenta a variação em percentual dos trabalhos publicados (Figura 5). 


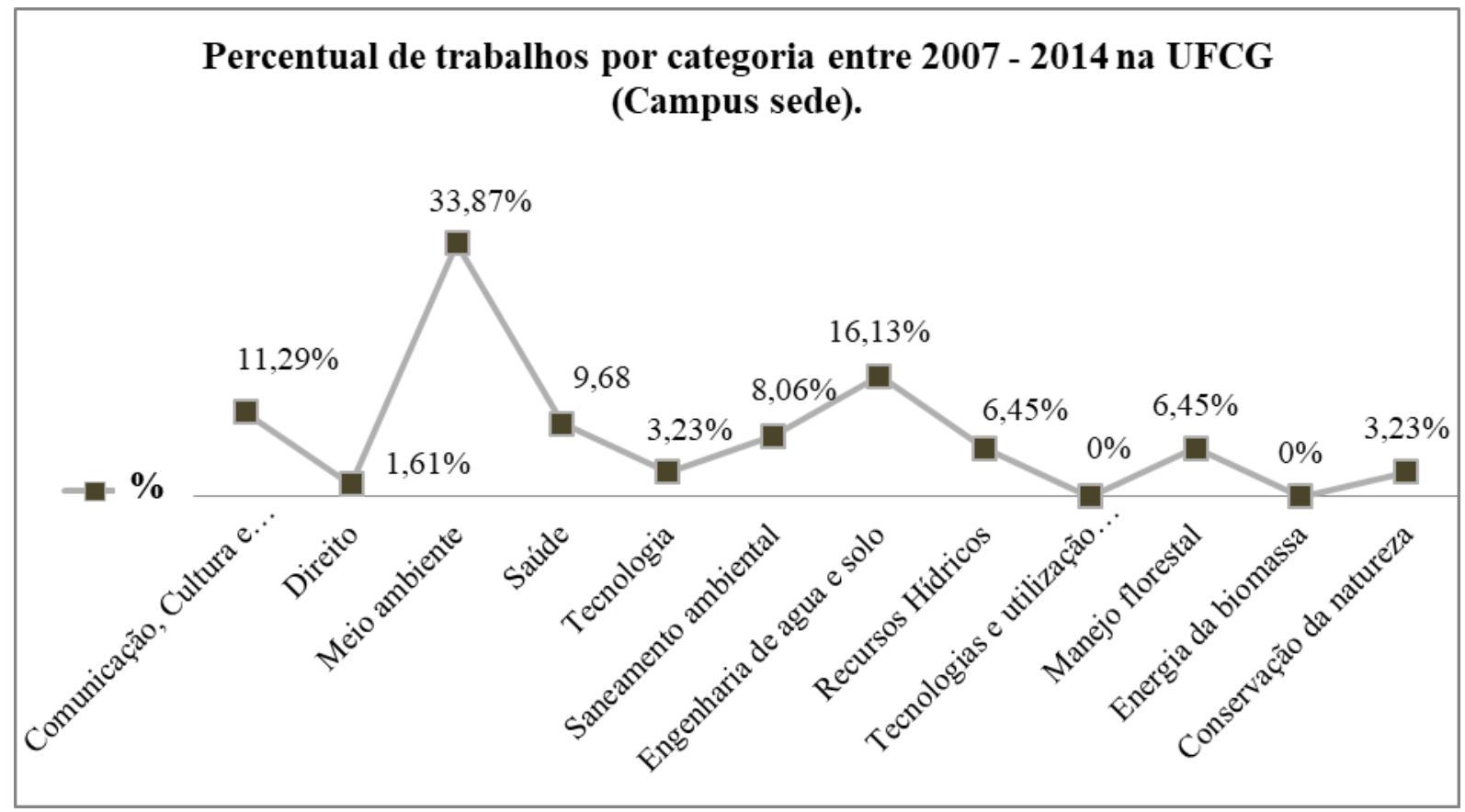

Figura 5: Descrição da porcentagem de publicações, nível pós-graduação.

Fonte: Dados da Pesquisa, 2017.

Observa-se que, aproximadamente, de 80 trabalhos publicados por ano apenas 5 preconizam a PNEA direta e indiretamente. Em uma análise de todas as teses publicadas pela instituição, menos de $10 \%$ dos trabalhos tratam da PNEA, essa porcentagem se concentra nas áreas de Engenharia Agrícola, Recursos Naturais e Engenharia de Materiais.

Alertamos que a maioria dos trabalhos publicados e defendidos em nível de Mestrado se repete no Doutorado, apresentando os mesmos objetivos, além de serem os títulos iguais, ou é alterado o título, porém, com os mesmos objetivos.

\section{Conclusão}

A partir dos dados analisados, observa-se que a Universidade Federal de Campina Grande apresenta um grande déficit na implantação da Política Nacional de Educação Ambiental (PNEA), na grade curricular dos cursos, bem como os projetos de pesquisa e extensão. Além disso, nas teses e dissertações, durante os anos de 2002 a 2015, a abordagem sobre as temáticas Meio Ambiente e Educação Ambiental são praticamente mínimas.

Isso representa uma importante mudança que a universidade terá que fazer, com 15 anos de formação (desmembramento da UFPB) é imprescindível, para o desenvolvimento profissional, que a temática seja abordada em todo contexto acadêmico, de forma continuada, permanente e interdisciplinar. 
A temática ambiental com sua dimensão abrangente pode, na formação profissional, contribuir de forma significativa, em direção à sustentabilidade. No caso do ensino, da pesquisa e extensão, oferecidas na Universidade Federal de Campina Grande, o futuro profissional pode estar apto não apenas a conhecer, aplicar e desenvolver tecnologias, mas também a avaliar seus impactos sobre o meio ambiente.

A pesquisa sugere que seja formada uma Comissão Institucional de Educação Ambiental, no campus de Campina Grande, cujo objetivo seja discutir, buscar soluções e avaliar ações da área ambiental. Além disso, a dimensão relacionada ao meio ambiente deve constar nos currículos de formação de professores em todos os níveis e em todas as disciplinas, com base na PNEA.

A Educação Ambiental é um componente essencial e permanente da educação nacional, sendo de responsabilidade das instituições educativas promover a Educação Ambiental de maneira integrada aos programas educacionais que desenvolvem.

Educar é construir, é libertar o ser humano das cadeias do determinismo social, reconhecendo no processo histórico um tempo de possibilidades inesgotáveis. Desta forma, podemos dizer que o processo educativo se configura como um "ensinar a pensar de forma autônoma". É um "que fazer dialogado, coparticipado", como afirma Paulo Freire.

Nesse sentido, Assmann (2001) coloca que a educação terá um papel determinante na criação da sensibilização social que, só assim, poderá "reorientar" a humanidade. A universidade deve ser comprometida com a transformação individual, social, econômica e ambiental, visando a uma melhoria na qualidade de vida de todas as sociedades existentes no planeta.

Conclui-se este trabalho, destacando a preocupação sobre os dados obtidos, uma vez que a universidade não apresenta, com predominância, no ensino, pesquisa ou extensão a dimensão ambiental, gerando assim, ausência do conhecimento critico-reflexivo sobre o assunto; o que traz consequências, sobretudo, ambientais. É dever da universidade despertar na população acadêmica a consciente preocupação com o meio ambiente e com os problemas que o envolve, transformando os cidadãos e a sociedade.

\section{Referências}

ABREU, I.G.; ABREU, B.S.; Morais, P.S.A. Educação Ambiental e sustentabilidade: Exercício de Cidadania. In: SEABRA, G.; MENDONÇA, I. T. L. Educação para a sustentabilidade e saúde global. João Pessoa: Editora Universitária da UFCG, 2009, 105p.

ANDRADE, D. F. Implementação da Educação Ambiental em escolas: uma reflexão. Revista eletrônica do mestrado em Educação Ambiental, v4, out/nov/dez, 2000, 15 p. 
ASSMANN, H. Reencantara a educação rumo à sociedade aprendente. 5o ed. Petrópolis: Vozes, $215 \mathrm{p}$.

BARBOSA, E. M, 2007. Introdução ao direito ambiental. Campina Grande: EDUFCG, 2001, 205p.

BRASIL. Constituição Federal. 1988.

BRASIL. Lei de Diretrizes e Bases da Educação Nacional. Lei 9.394 de 20 de Dezembro de 1996. BRASIL.

BRASIL. Política Nacional de Educação Ambiental. Lei 9.795 de 27 de Abril de 1999. Brasília, BRASIL.

CHAPANI, D.T. Educação Ambiental: ação-reflexão-ação no cotidiano de uma escola pública. Universidade Estadual Paulista Júlio de Mesquita Filho, Pósgraduação em Educação para a Ciência, 2001, 451p.

DIAS, G.F. Educação Ambiental: princípios e práticas. 9ª ed. São Paulo: Gaia, 2004, 551p.

FERREIRA, L. C. Ideias para uma sociologia da questão ambiental no Brasil - São Paulo: Annablume, 2006, 110p.

GUIMARÃES, J. et. al. Educação Ambiental na educação de jovens e adultos (EJA). Synergismusscyentifica UTFPR, Pato Branco, v. 03, n. 2-3, 2008.

GIL, A.C. Como elaborar projetos de pesquisa. São Paulo: Atlas, 2010, 200p.

LEFF, E. Epistemologia ambiental. São Paulo: Cortez, 2001, 240p.

LEFF, E. Saber ambiental: sustentabilidade, racionalidade, complexidade, poder. Petrópolis: Vozes, 2001, 343p.

MELGAR, M.J.A. Educação Ambiental nas Empresas: Um estudo de caso na Fischer Fraiburgo Agrícola Ltda. Universidade Federal de Santa Catarina, Pósgraduação em Administração, 2005, 100p.

MOURA, H.F.N.; ABREU, E.L. MORAIS, M.A.C. Educação Ambiental na educação de jovens e adultos: refletindo sobre as concepções dos alunos do proeja sobre meio ambiente e Educação Ambiental. In: SEABRA, G.; MENDONÇA, I.T.L. Educação Ambiental para a sociedade sustentável e saúde global. João Pessoa: Editora Universitária da UFPB, 2009, p. 663-669.

RIBEIRO, S.E.S. Em busca do equilíbrio perdido com a natureza: a relação entre uma comunidade urbana em João Pessoa - PB com a mata, o rio e os novos projetos sócio-ambientais, Universidade Federal de Pernambuco, Pós-graduação em Sociologia, 2007, 299p.

RICHARDSON, R.J.; PERES, J.A.S.; WANDERLEY, J.C.V.; CORREIA, L.M.;

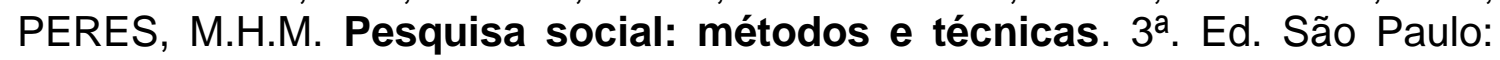
Atlas, 2011, 334p.

SILVA, D.J. Uma abordagem cognitiva ao planejamento estratégico do desenvolvimento sustentável. Universidade Federal de Santa Catarina. PósGraduação em Engenharia de Produção, 1998, 240p. 